\title{
Life Experiences of Women with Leprosy in South Korea
}

\author{
Hogi Jung ${ }^{1}$, Rayun Yang ${ }^{2} \&$ Yaki Yang ${ }^{3}$ \\ ${ }^{1}$ Non-Governmental Organizations, Chonnam University Graduate School, South Korea \\ ${ }^{2} 5 \cdot 18$ Archives, Gwangju, South Korea \\ ${ }^{3}$ Department of Nursing, College of Medicine, Wonkwang University, South Korea \\ Correspondence: Yaki Yang, Department of Nursing, College of Medicine, Wonkwang University, 460, \\ Iksandae-ro, Iksan, Jeonbuk 54538, South Korea. Tel: 82-63-850-6019. E-mail: ya3877@gmail.com
}

Received: February 5, 2020 Accepted: March 6, 2020 Online Published: March 7, 2020

doi:10.5539/gjhs.v12n4p46 URL: https://doi.org/10.5539/gjhs.v12n4p46

\begin{abstract}
Aim: The purpose of this study was to identify the life experiences of women diagnosed with leprosy in South Korea.

Methods: The study included seven purposively chosen participants from the Sorokdo Hospital (leprosy resident hospital). Data were collected through a series of in-depth individual interviews from January to July 2015. The data analysis method was based on Colaizzi's approach.

Results: The study's results showed that the experiences of women diagnosed with leprosy in South Korea consisted of 10 themes and 4 theme clusters: 1) A disease perceived as a state of damnation, 2) Irresistible karma, 3) Fading candles in the wind, and 4) A will to live.

Conclusion: These findings demonstrate that health care professionals should pay attention to not only treating the physical and psychological symptoms of leprosy patients but also attempt to influence the community and public culture in order to reduce the social stigma around this disease. The results of this study can help us in a better understanding of the lived experiences of women diagnosed with leprosy.
\end{abstract}

Keywords: hansen's disease, leprosy, life experiences, infection, phenomenography

\section{Introduction}

Leprosy, also known as Hansen's disease, is a chronic infectious illness caused by the bacteria Mycobacterium leprae and Mycobacterium lepromatosis (Han \& Silva, 2014; World Health Organization [WHO], 2019). These species of bacteria infect human skin and nerve tissues, causing damage to both an individual's physical appearance and their sensation capabilities. Leprosy is a disease that affects hundreds of thousands of individuals per year (WHO, 2019).

Currently, about $99 \%$ of the general population in Korea possesses immunity from the aforementioned Mycobacterium, so the probability of transmission between people is extremely low. Even if someone is infected, they can be treated successfully with medication (Korean Hansen Welfare Association, 2019). Nonetheless, negative perceptions and prejudices around Hansen's disease within Korean society persist. According to the Hansen Human Rights Survey (National Human Rights Commission, 2005) more than 70\% of the members of general society have negative perceptions around Hansen's disease. A total of $78 \%$ of respondents stated that they would not want to use certain convenience facilities, such as bathhouses or barbershops, in order to avoid this disease.

In total, 9,632 Korean leprosy patients, with an average age of over 79 years, are treated by the Department of Disease Control of the Ministry of Health and Welfare. Among them, 7,304 developed a disability during the course of their illness. In addition to this, around 39\% of leprosy patients are detained in special facilities or settlements (Korean Hansen Welfare Association, 2019). The population of people with leprosy constitutes a low-income group that is restricted in terms of their available economic activities due to the social discrimination and prejudice that they face. Therefore, it is not exaggerated to state that they are the "minority of the minority" and are a group with the additional, overlapping challenges of being disabled, elderly, prisoners, and among the low-income class (Yang, 2014). 
Historically, Hansen's disease patients were abandoned by their families due to the pervasive levels of prejudice, and were, by extension, excluded from the community and forced to live in a state of social isolation. Under Japanese colonial rule, it was reported that forced isolation, heavy labor, and restrictions of bodily freedom were enforced for all leprosy patients. Following the 1945 liberation, the oppression and sacrifices that people with leprosy underwent under the rule of Japanese colonialism continued, and the rejection, not only from the state, but also from society and their families, continued. Following the Korean War, Hansen's disease patients were still unable to escape the control of their social oppressors and continued to live experiencing various inhumane treatments. In the 1960s, the Hansen's disease social settlement system was created in an attempt to return patients to society, but this was only a half measure (Jung, 2006). This strategy was only a partial solution because their new settlements still lay outside the residential areas of the general public, effectively isolating them.

Leprosy settlements were originally created for keeping individuals with this disease together and away from the general populace (Staples, 2014). The goal was to prevent the spread of this disease to the members of the population who were not suffering from it. In the 20th century, however, the treatment for this disease became increasingly successful with the creation of the multidrug therapy, and studies have since established that the illness is not as contagious or dangerous as once thought (Staples, 2011; Staples, 2014). However, leprosy communities have persisted and are maintained by individuals experiencing it, as well as their families, to the present day. Despite the fact that individuals were no longer forcibly confined to leprosy communities, they have willingly remained there. One of the reasons why leprosy communities have persisted is because of the constant fear among individuals suffering from this disease regarding what external communities would think of or do to them (Oluremi, Coker, Sridhar, \& Olaoye, 2013). Hence, they remain within their specialized communities where the inhabitants are well acquainted with the realities of their illness and the needs of others who suffer from the same disease.

Hansen's disease patients have been hurt more so by social prejudice than the disease itself (Kim, 2013), and tend to be extremely reluctant to expose themselves as they worry about their family's well-being (Han, 2014). They are also people who do not possess a voice in the area of social public opinion, as their power to struggle for their rights is weak (Joo, 2007).

Especially, in Korean society, female Hansen's disease patients seem to experience more discrimination than their male counterparts do, as they possess the overlapping vulnerabilities of being women and having this disease. According to the Survey on the Status of Human Rights in Hansen's disease (National Human Rights Commission, 2005), 9.3\% of the 301 female patients reported that they had been forced to have an abortion, while also stating that their rights to pregnancy, childbirth, and custody were violated. In the 1960s, childbearing was banned within Sorokdo hospitals, and male vasectomies were performed as a prerequisite for in-hospital marriages. Hansen's disease patients' right to child custody was, therefore, infringed, not only at the point of childbirth, but also by being forced to send their children off for adoption following delivery. Particularly, within the patriarchal Korean society, women tend to face greater discrimination and oppression than do men, especially women with disabilities who experience a double level of alienation as a result of their two statuses.

Women with leprosy in Korea are restricted in terms of both their social and economic activities when compared against men (Lee, 2011). Therefore, an in-depth exploration into the life of an individual who belongs to both social minority groups of being female and a Hansen's disease patient is required. The lived experiences of individuals suffering from leprosy have been largely left unexplored (John, Rao, \& Das, 2010; Staples, 2011). It is, therefore, important to understand their unique lived experiences, as they are living evidence showing how cultural views both shape and affect societal reactions to this disease (Abedi, Javadi, \& Naji, 2013). These responses are important in understanding the segments of the population at a heightened risk of suffering the worst effects of living with leprosy, such as women and the poor (Ramos et al., 2012; WHO, 2012).

Negative feelings towards individuals, particularly women, with leprosy are persistent. The psychological issues associated with women diagnosed with leprosy, and the resultant stigma aimed at them, include factors pertaining to their dignity, social status, employment opportunities, employment stability, family relationships, and friendships with members of their communities (Kaur \& Brakel, 2002). The fear of infecting their relatives has led many women with leprosy to seclude themselves from their families. Moreover, married women have the additional fear of having to divorce their husbands (Singh, Sinha, Banerjee, \& Jaswal, 2009).

Existing studies and records of Hansen's disease patients have been reported from the viewpoint of the participants. However, there are few accounts of the unique life experiences of women diagnosed with this disease. Although there exists an assumption that female Hansen's disease patients face greater amounts of discrimination, a comprehensive understanding of their lives and experiences is currently insufficient. 
In this study, we attempted to gain an in-depth understanding of the experiences of female Hansen's disease patients' lives through a phenomenological research methodology. This study intends to understand the lives of female Hansen's disease patient's through exploring their interactions with their past, and to understand it within the historical and cultural context of Korean society. The purpose of this study is to uncover basic data on the life of women with Hansen's disease that have not yet been explored and to then derive potential practical implications for nursing education and practices.

The purpose of this study is to understand how women with leprosy, in Korea, have experienced living with this disease. Furthermore, we would like to contribute to the theoretical foundations of nursing theories, practices, and education in treating leprosy patients, based on an in-depth understanding of the life and illness experiences of women with this disease.

\section{Methods}

\subsection{Study design}

This study was performed in order to understand the lived experiences of women with leprosy in South Korea using a phenomenological method.

\subsection{Participants and Ethical Considerations}

The study subjects included female Hansen's disease patients from the Sorokdo Hospital. To obtain the data, the study was certified by the Institutional Review Board (IRB No. 201407-SB-041). Researchers visited Hansen's disease and residents' associations to explain the purpose of the study and to request their cooperation; following which, participants were then introduced. The participants were selected through a purposive sampling method, excluding those with communication problems or that refused to participate. In this study, we interviewed one female Hansen's disease patient who lives in Sorokdo Hospital, and discussed, with the participants, diverse participants in terms of age, period of illness, and time of transfer to the hospital. The participants were informed of the aim and procedures of the research before providing written consent. They were also informed that they could withdraw their participation at any time before publication of the results. In presenting the results, each participant was assigned a pseudonym in order to maintain their anonymity.

\subsection{Data collection}

All of the interviewees were asked for their permission to be audio recorded, prior to the interview. Specific data collection utilized the following procedure. First, we explained the procedure before the interview, and confirmed via either phone call or visitation whether the interview would be possible. After setting the date, time, and place of the interview, the participants were then interviewed.

Second, we constructed a list of basic questionnaire items and questions for the interview process. The interview questionnaire included information on participants' name, birth year, place of birth, education, occupation, religion, marital status (including any children), family, economic status, current residence, illness history, contact information, interview location, and others. The start of the interview used an open-ended question, beginning with introductory requests, such as "Tell me about the life you have lived as a Hansen's disease patient," the timing of the disease's onset, personal and social awareness of the disease, hospital admission processes, disease treatment processes, settlement migration experiences, re-admission, and so on. Through this process, participants voluntarily developed an account of their lived experiences. The questionnaire was constructed by two professors, through utilization of the existing literature (Kim, 2013; Park, 2010). In addition to the interviews, we also collected other materials, such as letters, photographs, and images related to leprosy and its experience.

A total of seven participants were involved in this study, with 1-2 interviews conducted per person. The interviews lasted from two to three hours each. Following this process, the collected data were then transcribed. In the transcripts, nonverbal communication, such as laughter, silence, and head nodding, were also recorded in order to record the interviews as "vividly as possible." Additionally, diaries about participants' experiences and feelings during the interview process were written immediately following each interview, and were included as data in the analysis. The interviews for the data collection process were conducted until no new concepts emerged and the information became saturated. The data collection period was from January to July 2015.

\subsection{Data Analysis}

For data analysis, the recorded responses were first transcribed word for word. Subsequently, researchers listened to the recordings again in order to improve the accuracy and reliability of the transcribed data. The process followed the method described by Colaizzi (1978), with data collection and analysis taking place in a circular fashion. In the first stage of analysis, researchers read the transcribed data several times, focusing on the context 
and participant responses, and then selected significant statements. Similar expressions were grouped together and organized from among the extracted statements, and reconstructed into a more abstract fashion. This was followed by the extraction of themes by grouping similar content in the identified significant statements. Following this, similar themes were grouped and categorized into themes with higher abstractness. Data collection and analysis were performed simultaneously. Interviews were conducted until theoretical saturation was achieved, which occurred when no new content appeared in the interviews, and the same type of concepts and themes emerged during data analysis.

The trustworthiness of this study was evaluated using the hermeneutic cycle's concepts (Lincoln \& Guba, 1989). The concepts of credibility, dependability, confirmability, and applicability were evaluated in order to maintain overall research quality (Guba, 1981). Four methods were used to strengthen the data credibility. First, the researchers were trained in qualitative methods by another, more experienced researcher. Second, feedback on the data quality and interpretations were obtained from an experienced researcher in hermeneutic phenomenology. Third, researcher reviews were conducted by certain participants who were invited to provide feedback on the analyzed data. Fourth, researchers conducted a published work review to facilitate the interpretative process. Dependability, confirmability, and applicability were achieved through both a researcher audit and written notes that documented all of the methodological issues and decisions. Purposive sampling was deployed, with the goal to reach maximum phenomenal and demographic variation, as recommended by Sandelowski, Docherty, and Emden (1997), and saturation of the data was determined according to the recommendations of Morse and Field (1995). The researchers discussed potential biases and assumptions, encouraging each other to be open-minded when describing the lived experiences of participants. In addition, the researchers kept audit trails and notes concerning all interpretive and thematic decisions. Follow-up interviews, intended to clarify the results obtained, were conducted with respondents in order to gain a deeper understanding of their experiences, thus enhancing the study's overall trustworthiness (Sandelowski, 1986).

\section{Results}

The average age of the study participants was 78 years, and all of them had experience of marriage after hospitalization in Sorokdo Hospital. After bereavement, there are two people who live alone and five who live with their spouse. The birth place is Jeollanam-do 3, Jeollabuk-do 2, Chungcheongbuk-do 2, which seems to be related to the Sorokdo Hospital located in Jeollanamdo. The pathway of hospital admission to Sorokdo Hospital is diverse. The hospitalization route was confirmed by the invitation of the family, the hospitalization through the protection center, and the forced acceptance, it can be seen that the hospitalization procedure of the Sorokdo Hospital was not formulated at that time. At the time of admission, the minimum age is 16 and the maximum age is 28 . The period of living in Sorokdo Hospital varies from 38 years to 67 years. Participants can see that they have lived in Sorokdo Hospital for a very long time, including the critical period of their lives.

The phenomenon of Korean women with Hansen's disease experiences included four essential themes: (1) A disease perceived as a state damnation, (2) Irresistible karma, (3) Fading candles in the wind; (4) A will to live.

\subsection{A Disease Perceived as a State of Damnation}

When the participants became aware that they had Hansen's disease, they experienced uncontrollable feelings of fear and helplessness. They developed the early symptoms of leprosy and had traumatic experiences whereby their bodies were transformed by the disease. Although they lived in houses with their families, they were forced into accepting further help due to the rejection of their communities and the urgent need for leprosy treatment.

\subsubsection{Hideously Deformed Body}

All of the participants experienced feelings of embarrassment and fear due to the early symptoms of leprosy, as well as expressing anxiety around their deformed bodies, irrespective of their individual willpower. Through the leprosy-induced changes in their physiologies, they became highly aware of their own illnesses, and negatively aware of their bodies.

Maybe I became sick when I was nine. My whole body hurt for no reason. I did not know that it was leprosy at the time. I was often hurt and not well healed. Fingers and toes slowly declined and gradually disappeared. (Participant 2)

Maybe I was about 15 years old. I was always tired, I always wanted to lie down, and then I had eyebrows, hands, and feet until then. One day my face was red, then white, and some days I was pretty and some days I was ugly. Then my face became swollen and turned into like clouds of heaven, so that people could not recognize me. After a while, my eyebrows began to disappear. (Participant 7). 


\subsubsection{Lives in Hiding}

Participants began to live in hiding following the onset of their illness. People with Hansen's disease were perceived, not as those who needed treatment, but as individuals who had to be expelled for the sake of the community's social hygiene and safety. In this situation, the family hid the person who had developed Hansen's disease in their home, and then had to live like outcasts as a result. However, the disease continued to worsen due to the lack of appropriate treatment. Hansen's disease placed heavy burdens on, not only the person with it, but also on their families.

When I am in my room, my family puts food in the room. I eat rice but I cannot go outside. I could go out only at night. My family can get in trouble because of me. I lived in the room for a certain period, and later went to Sorokdo Hospital. (Participant 1)

When I go around town, people were gossiping around here and there. I could not go out. I lived in only my room for three years. My family has also suffered a lot. My family could not even collect spring water in town. (Participant 3)

\subsubsection{Deciding to Admit Oneself into Hospital in Order to Live}

Participants left their families to receive treatment for leprosy or, alternatively, to escape persecution from their communities, and, subsequently, entered a leprosy facility. In terms of the socio-historical context, this period is understood to be that which followed the enactment of the Prevention Act which aimed to strengthen the isolationist policy on people with Hansen's disease. The Chosun Governor General opened a specialized hospital in Sorokdo for the treatment of Hansen's disease, called Jahye-uiwon, which then began accepting patients in 1996. This not only forced people into hospitals based on the isolationist policies of Japanese colonial rule, but also hospitalized them in order to allow them to survive in a society where their lives were threatened. Participants were forced to choose to live as a human being whose fundamental rights were threatened before they had even reached adulthood. This resulted in a struggle for people with Hansen's disease to survive, involving a forced deportation from their own communities.

If I tried to get on the bus, people would interfere with me. They even kicked my body. I was ignored. The cops came and told me there was a place with good medicine. I was admitted to the hospital after going along with the police. (Participant 4)

When I went to Sorokdo Hospital, I had many thoughts whether I would come out alive or die. I am going to cure the disease, but I was afraid to leave my parents. (Participant 2)

\subsection{Irresistible Karma}

The compulsory hospitalization for the treatment of leprosy was a result of the challenging lives and inhumane treatments faced by people with this disease, rather than solely for the medical treatment offered. Just as there is an expression of "the way to the charnel house," the Sorokdo Hospital was seen as a place for gaining social acceptance, rather than one for a cure, as well as one in which people had to endure hard labor. Despite the worsening health conditions in this hospital, due to the difficulties of treatment, the hard labor prescribed to them became unbearable. Additionally, regardless of a person's willpower, some would inevitably marry, whereby their husbands' enforced vasectomies would deprive them of the right to bear children. Even if they managed to give birth to a child, in order to prevent the spread of leprosy, these children were then forcibly sent away to nurseries, depriving their parents of custody.

\subsubsection{Prisons without Bars}

The hospitals selected for leprosy patients' treatment and survival were closer to acceptance facilities than to actual hospitals. All participants were housed in either the Sorokdo Hospital (on an island) or the Inland Hospital from 1944 to 1991, where they experienced both the liberation in 1945, and the chaos of the 1950 Korean War. In the Sorokdo Hospital, the employee zone is strictly divided into the patient (or "toxic") and staff (or "untoxic") zones, with the borderline being thoroughly monitored. Participants were admitted to the hospital for treatment, but were unable to concentrate on their recovery, experiencing both oppression and exploitation, such as the forced labor resulting in malnutrition. It also appears that women, in particular, had to develop passive strategies in order to survive under the unjust conditions and persecution within the hospital and its strict rules. In particular, as women, it was difficult to endure life within a detention center, as there were no safe psychological spaces to allow them to feel troubled or sad about their deformed body shapes.

I cannot go outside because of the staff rules. I can get out if I get a travel permit. If leave without permission, I will be beaten and confined. Listening to that, we never did anything against the rules. (Participant 5) 
I have to be beautiful because I'm a woman, I could not afford to think like this. I cannot function as a woman, this idea was a luxury. When a patient dies, people put the body in a vial for study or put it in a big sump. I saw the baby who was forced into abortion in the glass bottles. (Participant 7)

\subsubsection{Unwanted Marriages}

Participants were married (either for the first time or remarried) to other leprosy patients at the acceptance facility. On Sorok Island, a facility for accepting leprosy patients, the men and women lived separately. However, following 1936, men were allowed to live with women after having undergone a vasectomy, with the intention to mentally stabilize the patients and eliminate the chances for disagreements. The marriage of female patients with Hansen's disease is presented as a form of matchmaking, but it is, in actuality, a forced marriage unrelated to their desires. However, although they were marriages without the input of the participants, they did serve to help people overcome the loneliness resulting from the difficult hospital life, relieve the anxiety caused by the separation from their families, and brought about a sense of psychological stability. The relationships formed by these marriages were distinct from the general sense of community within the hospital and, for the female Hansen's disease patients, their in-hospital spouses had more meaning to them than did their original spouses.

At that time, in Sorok Island, there are few women but many men. I married easily because I thought I could go home after the illness was cured. Often men would come and propose to marry me. If I refused, they punished me and forced me to marry. I think I did not live like a human being, (Participant 6)

Some aunt suggested me to live with him. When you live alone, you can feel lonely. I was married when I was 19. I was so lonely and hungry. I did not have a love for my husband, but I lived with trust and dependence. (Participant 4)

\subsubsection{The Child Who has not been Hugged}

Two of the participants were denied any opportunity to become pregnant as a result of their husbands' vasectomies under the hospital's marriage rules, and did not experience motherhood as a result. Two of the participants were forced into miscarriages by the hospital after it became aware of their pregnancies. In order to claim the legitimacy of the enforced vasectomies, claiming that Hansen's disease is inherited, the hospitals subsequently deprived people with leprosy their rights to pregnancy, childbirth, and custody by saying "another crow always comes out from a crow."

Three of the participants gave birth to children. However, when the child became nine months old, they were forcibly separated from their parents and sent to a nursery. Even though the disease is not contagious, patients had to send their children away to a nursery under the rules of the hospital. Sorokdo Hospital gave parents an opportunity to meet with their child once a month, with the children remaining in the nursery and the parents in the hospital, creating a distance between them. The children's crying was reportedly loud, and it was thus called "the place of crying" (National Sorokdo Hospital, 1996). Women with Hansen's disease who became mothers were forced to suppress their maternal instincts in order to live within the hospital.

I have no child. My husband had a vasectomy. I was born as a woman, but I did not have the chance to experience childbirth. (Participant 4)

I was pregnant from my marriage before admission, and I had to bear the baby after going to the hospital. The child was forced to go to nursery school when they reached nine months old, and I had surgery to prevent further pregnancies. (Participant 6)

I went to the hospital and the doctor said I was pregnant. He told me I was going to bear a leprous baby. He forced me to have an abortion. I also had a tubal resection so I could live longer in the hospital. (Participant 1)

\subsection{Fading Candles in the Wind}

Despite the ending of forced isolation and the creation of the opportunities to live in settlements, women with Hansen's disease continued isolating themselves from society. In particular, women with this disease had more restrictions placed on their possible social activities than did the men. To compensate for their deformed appearances, some underwent eyebrow tattooing. Unlike healthy women, those with leprosy are restricted in their ability to give birth to and nurture children. Women with Hansen's disease demonstrate a sense of sorrow and responsibility for their grown children, and live by hiding their existence out of a sense of worry for their children's future. These same women reportedly live the rest of their lives recalling the difficulties of their pasts.

\subsubsection{Sorrow}

Since the late 1940s, the settlement movement of leprosy patients began in Korea, and many villages have 
subsequently been formed from the early 1950s. Some of the participants migrated to settlement villages at this time. However, this settlement was built on the outskirts of society where most people did not live, and it was called "Hansenin Village." It has since caused greater discrimination and exclusion. People with Hansen's disease still felt anger, frustration, and sadness about the continuing discrimination. In these settlements, people with Hansen's disease are mainly engaged in agriculture and animal husbandry in order to make a living. Married couples work in these settlements, but any form of social life outside of the settlement is primarily held by the men. Therefore, the women in these settlements live their lives isolated from general society, unless they actively attempt to expose themselves. As a result, these women remain, generally, separated from wider society as they tend to stay within the areas of their settlements.

People sit next to me at first, but once they see my face they move to the side. When people see me and get angry without reason, I cannot say anything. I've lived my life like a sinner. (Participant 5)

I went to the community, but I cannot live there. Even if people do not say "I do not like you," it's still hard for me to come out in front of people because of my leprosy. The people living here are all lepers and we are rather relaxed. (Participant 2)

\subsubsection{Parts of the Body Deformed by Leprosy}

Participants in the study presented with deformed body shapes due to their leprosy. In particular, five patients had the more typical symptoms, such as a loss of fingers and toes, protruding eyes, and facial deformities. Participants reportedly felt that they created a sense of repulsion and a fear of contagion within the non-Hansen's disease populace because of their physical symptoms, and, as a result, felt cursed, fearful, and ashamed. Particularly, for women, body shape deformities are associated with a loss of femininity due to the socially accepted standards of beauty, resulting in a greater sense of loss than that of their male counterparts. They try to relieve these symptoms through practices like eyebrow tattoos and wearing ancillary equipment, but continue to feel the burden of their infections on top of the consequences of engaging in potentially unsanitary procedures.

I cannot catch things by hand anymore. It gets worse and worse. My eyesight is also getting worse. Other things are okay, but my hands have a lot of difficulties. When I buy things, I am uncomfortable with my blunt hands. When I pay for the ticket, people collect it with tong-like tools. (Participant 1)

I did not have eyebrows, so I had a tattoo. I tried to be pretty, but it was expensive and the wound was not healed. (Participant 2)

\subsection{A Will to Live}

Participants diagnosed with leprosy tend to report experiencing an unbearably cruel life. However, they may now live in some level comfort while residing at Sorokdo Hospital. They were also, reportedly, waiting for death to end their pain. Conversely, to relieve the suffering they experienced, participants attempted to purify their minds by praying, hoping for religious assistance with their survival. Children are another means of living for women. They desperately desire their children's happiness, without being forced to reveal themselves or their illness.

\subsubsection{A Sprout on a Dead Tree}

Research participants who were parents expressed feelings of sorrow and sadness about their children. The children of people with Hansen's disease were stigmatized and labeled as unaccounted, to the point that they were often met with resistance when they desired to be educated like children of people without leprosy. When they reached adulthood, they were often restricted in their job and marriage opportunities. Parents with Hansen's disease often hide their existence for the sake of their children's futures. Since women with leprosy cannot play a formal role in their children's development, they regard it as an aspect of life with Hansen's disease and adopt a passive strategy (through hiding themselves) in order to overcome this drawback and help the child have a successful life. To leprosy patients, their children are what give their lives meaning.

To me, my children are the meaning of my life. (Participant 6)

It was a secret that we had leprosy, because it could interfere with the marriage of my child. I do not want to be harmful to my precious children. I wish my children would go out into society and live just like everyone else. (Participant 3)

\subsubsection{Getting Help by Praying}

Another way that participants release the psychological pain caused by Hansen's disease is with religion. They receive comfort and peace from their religion, and this then becomes the power that holds their lives together.

I have overcome my difficulties with my beliefs. The illness given to me is inevitable. I have thought many times 
that I want to die, but because I live with my belief, I think that I will go to hell if I think like this. I now rely more on God than on my brothers. (Participant 1)

\section{Discussion}

This study attempted to understand the lived experiences of women with Hansen's disease in Korean society. Throughout the course of their lives, these women have been systematically excluded from their communities as "abnormal" women. They are patients with leprosy who have experienced both social isolation and discrimination. In addition, unlike their male counterparts who may have partial social lives due to the increased availability of economic activities, these women demonstrate passive lifestyle habits through the adoption of a survivalist manner of living by limiting themselves to permanently remaining in their settlement villages. The implications of this study are as follows.

Hansen's disease is a traumatic experience, similar to a state of damnation. All of the participants experienced embarrassment, shame, and stigma due to their bodies changing in the early stages of leprosy. It has been discovered that they often live in small rooms hidden in the house in order to avoid societal persecution. This is similar to the life of Taiwanese and Nepalese people with Hansen's disease (Shieh, Wang, \& Lin, 2006), who had attempted recovering at home, or simply living in a single room, before being diagnosed with leprosy.

According to the results of public awareness surveys on Hansen's disease conducted by the National People's Rights Commission in 2005, it is recognized that social awareness of the human rights problems faced by people with this illness, and on the disease itself, is gradually improving. However, there still exists widespread discriminatory attitudes. This reflects the fact that discriminatory and exclusionary attitudes rooted in daily life do not change easily, even if they are addressed by policy or institutional amendments of the law. In particular, for women with Hansen's disease, they tend to be more worried about the bodily deformities due their illness when compared against their male counterparts. In order to overcome the stigma around Hansen's disease, the processes leading towards prejudice, discrimination, and stigma should be addressed. A disgusting physical image, fears of contagion, and a false belief that leprosy is incurable are the root causes of the inhumane treatments faced by people with leprosy. Therefore, there is a need for continuous publicity and enlightenment around Hansen's disease, including the fact that people cannot be infected after receiving treatment. In addition, individual-level coping skills, self-management skills training, counseling, etc. should be provided in accordance with the unique characteristics of each individual. The concealment of the sickness due to social stigma towards leprosy can result in delaying the diagnosis of the illness and, thereby, worsen the condition by causing the person to receive improper treatment.

It can be seen that female Hansen's disease patients live in a state of irresistible karma. The occurrence of leprosy completely unravels a person's life. It has the same effects as experiencing a state of damnation via the impersonal treatments conducted by facilities, such as surveillance and detention. Hansen's disease hospitals, such as the Sorokdo Hospital, are places of treatment for this disease, as well as places of isolation and exclusion aimed safeguarding patients against uninfected peoples. For them, life is a constant struggle within the strict rules of the hospital. As a result of this study, the living conditions of the detention facilities were expressed in various forms, such as a lack of nutrition, forced labor, dissection of the body, forced confinement, prohibitions towards leaving, persecution, and improper treatment.

During the detention process, the stripping away of maternity rights is considered as the greatest pain suffered by women. The results of this study corroborate the findings of Shieh et al. (2006) showing that, when women with leprosy gave birth in the 1950s and 1970s in Taiwan, they experienced guilt and bitterness due to being forcibly separated from their children. Many of the women with Hansen's disease experience difficulties in the availability of potential economic activities due to their physical disabilities as caused by the disease's effects. Women with this disease were unable to give birth to children due to their husbands' enforced vasectomies, or were, alternatively, separated from their children if they managed to give birth. In the study by Choi (2002), it was confirmed that elderly people diagnosed with Hansen's disease are oftentimes living with disabilities, whether or not they have children. Economic difficulties can increase the challenges of accessing medical services, and the absence of children can also increase a person's lack of emotional support. There needs to be a way to provide both medical and emotional support for people with leprosy, and to improve the quality of life for those without dependents.

A rewarding experience for those women who are denied motherhood, a marital relationship in the community aimed at alleviating the emotions of loneliness due to their disconnected life structures, and self-help groups. In recent years, efforts have been made to recognize the suffering of these people and to accept them as members of society. For example, for the first time a lawsuit was filed against the Korean nation by 19 people with Hansen's disease, including claims about forced abortions and discontinuance. In addition, supporting certain services, such 
as eyebrow tattoos and artificial aids, can be considered as a way to alleviate the appearance-based challenges of women with Hansen's disease.

As found by this study, migration to the aforementioned settlements seemed to give a sense of freedom to women with leprosy, but, in reality, they were subject to further discrimination in the form of societal isolation.

Women with Hansen's disease have been forced to live like fading candles in the wind. It has been confirmed that women with this disease isolate themselves from society and demonstrate attitudes that conform to social prejudices. Rather than exposing themselves to possibly negative experiences and greater suffering, isolation is believed to be a strategy aimed at minimizing these factors by remaining within a small and isolated space, and to maintain some measure of psychological stability and freedom. In particular, female Hansen's disease patients appear to feel cursed, ashamed, and guilty. As a woman, one's body shape is associated with their relative femininity and, as a result of the disease-induced physical deformities, they experience heightened feelings of loss. The results of this study indicate that the attitudes towards the physical impairments were negative, and the degree of resultant depression was higher in women with Hansen's disease than in their male counterparts (Kim, 2009).

A system is, therefore, needed to support the livelihoods of women with leprosy so that they can accommodate their lives and live comfortably. Many women with Hansen's disease have to die without their spouse because they tend to live longer than their husbands do. In addition, there are no existing structures aimed at resolving either the anxiety or the fear related to death because they cannot live with their families, regardless of whether or not they have children. Women with Hansen's disease are accustomed to earning a living alone, have long become used to social discrimination and exclusion, and tend not to claim their own rights or express their desires. Therefore, spiritual interventions can be considered in order to provide programs, such as exclusion, counseling, and recall therapies aimed at gaining an acceptance of one's life as a discriminated individual, and to provide comfort in the preparation for one's death.

\section{Conclusion}

This study attempted to understand the lived experiences of women with Hansen's disease, and confirmed the significance of a life lived with others. These are women and other social minorities who are living with physical disabilities caused by their leprosy. We hope that this study will be a starting point for an increased understanding of the challenging lives of women with Hansen's disease. Based on the results of this study, the following suggestions are made in terms of nursing research, practice, and education. First, in this study, the lived experiences examined were only those of women with Hansen's disease residing in Sorokdo Hospital. Repeated studies are required for other women living in settlements or at home. Second, based on the results of this study, we suggest the deployment of medical personnel and the development of a management system that can improve the accessibility to medical services of people with Hansen's disease residing in communities. Third, continuous promotions and enlightenment interventions are required in order to overcome the stigma of this disease as a first step towards the integration of people diagnosed with leprosy within their communities. This phenomenological study was performed with a purposively selected sample and consisted of seven leprosy patients and, therefore, the results are limited in terms of their generalizability. In future investigations, it may be possible to recruit more participants from various settings. More data from future studies are needed in order to supplement the conclusions of this study.

\section{Acknowledgments}

This work was supported by the National Research Foundation of Korea (NRF) grant funded by the Korea government (MSIT) (2019R1F1A1056424).

\section{Competing Interests Statement}

The authors declare that there are no competing or potential conflicts of interest.

\section{References}

Abedi, H., Javadi, A., \& Naji, S. (2013). An exploration of health, family, and economic experiences of leprosy

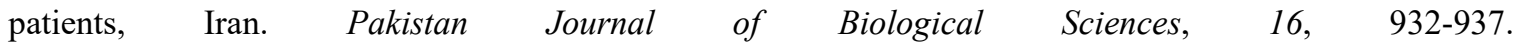
https://doi.org/10.3923/pjbs.2013.927.932

Choi, W. G. (2002). Practice of the bio-power and social welfare - discourses on the compulsive vasectomy to the inmates of asylum. Journal of Critical Social Welfare, 12, 143-181.

Colaizzi, P. F. (1978). Psychological research as the phenomenologist views it. New York: Oxford University Press. 
Guba, E. (1981). Criteria for assessing the trustworthiness of naturalistic inquiries. Educational Technology Research and Development, 29(2), 75-91.

Han, S. M. (2014). On the life and history of those who have Hansen's disease, and the impossibility of testimony. Journal of Democracy and Human Rights, 14(3), 125-157.

Han, X. Y., \& Silva, F. J. (2014). On the age of leprosy. PLOS Neglected Tropical Diseases, 8(2), e2544. https://doi.org/10.1371/journal.pntd.0002544

John, A. S., Rao, P. S., \& Das, S. (2010). Assessment of needs and quality care issues of women with leprosy. Leprosy Review, 81, 34-40.

Joo, Y. J. (2007). Social works for the Hansen's disease patients in post-liberation Korea: Focusing on the works of Catholic organizations. The Research Foundation of Korean Church History, 29, 221-252.

Jung, K. S. (2006). Dissolution of settlement village and network of migration in Hansen's disease ex-patient communities. Society and History, 69, 43-81.

Kaur, H., \& Brakel, V. (2002). Rehabilitation of leprosy-affected people: A study on leprosy affected beggars. Leprosy Review, 73, 346-355.

Kim, K. H. (2009). Oppression and discrimination against Hansen's disease: Some implications for social welfare interventions. Korean Journal of Social Issues, 10(1), 9-37.

Kim, S. L. (2013). Hansen's Oral Life Histories and Healing. Korean Journal of Medical History, 22(2), 389-419. https://doi.org/10.13081/kjmh.2013.22.389

Korean Hansen Welfare Association. Cases under of service in 2018. Retrieved June 25, 2019, from $\mathrm{http}: / /$ www.khwa.or.kr/sub.asp? maincode $=482 \&$ sub_sequence $=529 \&$ sub_sub_sequence $=\&$ mskin $=\&$ exec $=\mathrm{v}$ iew\&strBoardID=kui_529\&intPage $=1 \&$ intCategory $=0 \&$ strSearchCategory $=\mid$ _name $\mid$ __subject $\mid \& s t r S e a r c h$ Word $=$ \&intSeq $=9379$

Lee, J. S. (2011). A study on the moderating effects of social support in the relationship between the stigma and social avoidance \& distress of individuals with leprosy. Journal of Rehabilitation Research, 15(3), 107-130.

Lincoln, Y. S., \& Guba, E. G. (1985). Effective evaluation (4th ed.). San Francisco: Jossey-Bass Publication.

Morse, J. M., \& Field, P. A. (1995). Qualitative Research Methods for Health Professionals. London: Sage.

National Human Rights Commission of Korea. (2005). Survey on the human rights of Hansen's. Seoul: Author.

National Sorokdo Hospital. (1996). History of Sorokdo Hospital 80 years. Seoul: Yakup Newspaper.

Oluremi, J. R., Coker, A. O., Sridhar, M. K. C., \& Olaoye, R. A. (2013). Solid waste management in a leprosarium in Southwestern Nigeria. Civil and Environmental Research, 3(10), 98-106.

Park, K. D. (2010). Change of meaning in Sorok Island and actions taken in the Hansen community. Korean Regional Sociology, 11(2), 91-130.

Ramos, J., Martinez-Martin, M., Reyes, F., Lemma, D., Belinchon, I., \& Gutierrez, F. (2012). Gender differential on characteristics and outcome of leprosy patients admitted to a longterm care rural hospital in South-Eastern Ethiopia. Journal for Equity in Health, 11(3), 1-7. https://doi.org/10.1186/1475-9276-11-56

Sandelowski, M. (1986). The problem of rigor in qualitative research. Advances in Nursing Science, 8, 27-37. https://doi.org/10.1097/00012272-198604000-00005

Sandelowski, M., Docherty, S. \& Emden, C. (1997). Focus on qualitative methods qualitative metasynthesis: Issues and techniques. Research in Nursing and Health, 20, 365-372. https://doi.org/10.1002/(SICI)1098-240X(199708)20:4\%3C365::AID-NUR9\%3E3.0.CO;2-E

Shieh, C., Wang, H. H., \& Lin, C. F. (2006). From contagious to chronic: A life course experience with leprosy in Taiwanese women. Leprosy Review, 77(2), 99-113.

Singh, S., Sinha, A. K., Banerjee, B. G., \& Jaswal, N. (2009). Participation level of the leprosy patients in society. Indian journal of leprosy, 81(4), 181-187.

Staples, J. (2011). Interrogating leprosy stigma: Why qualitative insights are vital. Leprosy Review, 82, 91-97.

Staples, J. (2014). Communities of the afflicted: Constituting leprosy through place in South India. Medical Anthropology, 33, 6-20. https://doi.org/10.1080/01459740.2012.714021

World Health Organization. (2019). What is Leprosy? Retrieved June 25, 2019, from 
https://www.who.int/lep/disease/en/

Yang, Y. K. (2014). Life experiences of Korean patients with Hansen's disease in Sorok Island Hospital. Journal of Korean Academy of Nursing, 44(6), 639-648. https://doi.org/10.4040/jkan.2014.44.6.639

\section{Copyrights}

Copyright for this article is retained by the author(s), with first publication rights granted to the journal.

This is an open-access article distributed under the terms and conditions of the Creative Commons Attribution license (http://creativecommons.org/licenses/by/4.0/). 